\title{
The Relation between Language and Culture (Case Study Albanian Language)
}

\author{
Kadri Krasniqi \\ English Language and Literature, Faculty of Languages, Cultures and Communication, South East European University, \\ North Macedonia
}

Copyright $(2019$ by authors, all rights reserved. Authors agree that this article remains permanently open access under the terms of the Creative Commons Attribution License 4.0 International License

\begin{abstract}
For centuries, language researchers, theorists, linguists, educational psychologists, and an ocean of scholars have agreed that language and culture are closely related and affect each other in so many ways. They support each other in so many sensitive situations, they complement each other on many occasions, they reflect each other on many aspects, and they protect each other through conflicts and wars. Above all, for centuries, they somehow managed to survive by being inseparable; 'like the skin and flesh of our body'. The meanings of a particular language anywhere in the world represent the culture of a particular social group. Therefore, without having direct access to its language, it is impossible to understand its culture, tradition, beliefs, values and customs of that particular social group. This is because of their intimate connection or bond they have singularly and together. Learning a language, therefore, is not only learning the alphabet, the letter sounds and the shapes, the meaning, the grammar rules, and the structure or arrangement of words, but it is also learning the behavior of the society and its cultural customs. Thus, language teaching should always contain some references to the culture. On the one hand, we are thankful to the language that provides us with important tools we use to express and communicate our thoughts and ideas on a daily basis. On the other hand, we are also thankful to the values and customs of our culture in the countries we live and grow up in the shape or construct the way in which we think and behave to a certain degree. The main purpose of this paper is to identify some of the characteristic relations or bonds that exist between any language and culture in anywhere in the world, with reference to Albanian language and culture.
\end{abstract}

Keywords Language, Culture, Relation, Expose, Hide, Influence

\section{Introduction}

We all know and agree that language is the system of communication used by a particular community, tribe, region or even the whole country. Whereas, culture is the sum of human experience of people that share the same language, geographical position and traditions, which could extend as far as the size of a peninsula or even the size of a continent. Countries of the continents such as: Asia, Africa, and South America have a lot in common regarding language and culture. It has been argued that culture is a product of history over time; its survival through various wars, through various immigrations, through endless and brutal explorations, and the constant evolution of language. Therefore, language and culture have a very complex and homologous relationship that makes them inseparable. We cannot use one and ignore the other because of their complexity. Language is complexly intertwined with culture. They have evolved together, they have survived together, they have fought together endless wars and unrests, and they have influenced one another in a long and endless process of human development. In this context, almost hundred years ago, one of the most influential American cultural anthropologists of the $20^{\text {th }}$ century (Kroeber, 1923, p.2) said, “... culture, then, began when speech was present, and from then on, the enrichment of either means the further development of the other." We all should accept that, as the result of this associated complexity, evolution and influence, language and culture protect each other in such a way that it is impossible to separate them. It makes it even harder if a language is isolated and its people are conservative; like Japanese people, whose culture has a great influence on their language and on their societal discipline, too.

In addition, language and culture complement each other through various forms, such as; words, gestures, behavior, attitudes, discipline, work, and history. Although, there are languages that expose culture to a certain extent, there are also cultures that hide their language to a similar or even greater extent. Some languages go as far as exposing their peoples' culture as either being lazy or hardworking, sensitive in temperament or calm, selfish or altruistic, and collective or individual. Most of the languages anywhere in 
the world, if not every single language in the world represent its culture, like a Japanese author said: "We can easily find out what people are interested in by looking at the language they speak. Japanese language contains various phrases concerning the seasons, climate and nature. Mongolian has a huge amount of vocabulary concerning animals, whereas French is the best language for describing food in detail", (Ayumi, 2009, p.1).

\section{Methodology}

The current paper employed two types of research methods such as quantitative and qualitative - otherwise known in research methodology as the mixed method research design. The quantitative method is employed so that information is retrieved from the population, who represent the large number of the participants in the study, and other reference materials data that would be easy to measure and analyze. Whereas, the qualitative method is employed in order to retrieve quality information through many visits, meeting, and interviews with locals and well respected members of the community. The current study took place over the period of two years, precisely from beginning of 2017 till late summer of the 2018 .

Language as a mirror of culture in a country or ethnic area always reflects aspects of that culture. Language also reflects many unique aspects of a culture, in particular, Balkan languages. This paper will examine some of the most influential characteristics of the Albanian language and how Albanian culture is embedded in the language.

First of all, one of the most noticeable characteristic of the Albanian language and Albanian people is the value of hospitality. It could be said that it is this value that differentiates them from the rest of the world. On the one hand, it makes them prouder and differentiates them from many other cultures and languages. On the other hand, though, it makes them poorer and more vulnerable when compared to other peoples. Nevertheless, Albania, rather than any area in the Balkan inhabited by Albanians, has an incredible hospitable culture and has its own traditions of courtesy. Hospitality means a great deal for every single Albanian family and is embedded in the tradition of the Albanian people for centuries and still continues very strongly in most part of the country.

Despite hospitality costing a lot, sometimes leaving families financially struggling for few days or weeks, and perhaps affecting their family's well-being for weeks to come, they would still do everything for a guest or a person they invite for dinner or for any other occasions. Most families, with respect to hospitality and its traditions, may go as far as to spend a month's salary to feed a visitor. "Some families overdo it and give the person they invite for dinner so much food that they could "feed an army," even though the host family might go hungry next day."(Lingo, 2012, p.5). The following day when children ask their mother, "what's for dinner mum?" their mother would sorrowfully answer, "left overs from yesterday!" Then again the following day, "what's for dinner mum?" again a sorrowful answer from mother, "left overs form a day before!" and this sorrowful conversation between the children and their mother may go on for several days to come.

This attitude of the Albanian people, anywhere in the world, towards a visitor or a guest shows that Albanian culture is very hospitable; sometimes to the extreme. As a result of this generous tradition, after taking into account the cost of hospitality, time, effort and the financial consequences after the guest leaves the house; is it worth following or continuing with this generous tradition that makes them proud and differentiates them from the any other culture? One answer would be a simple and easy one, No! It is time for the Albanian people and their hospitality to change and behave like Europeans do or continue to eat the left overs for the rest of the week.

Besa, "to keep the promise" is another noticeable characteristic of the Albanian language and culture. Besa is the Albanian code of honor and a major component of Albanian culture. It is one of the highest and the most important concept of the Kanuni (a comprehensive compilation of Albanian traditional customs and cultural practices, codified by Leke Dukagjini earlier than the Middle Ages). Above all, Besa means taking care of those in need, protecting them, and being hospitable to every single human being you have given your promise. A most notable act of the Albanian "Besa" was shown during the Second World War, when some Albanians saved and protected more than 2000 Jewish people during the Holocaust. Instead of hiding the Jews in attics or in the woods, the Albanians dressed them like Albanians, even gave them the Albanian names and treated them as part of the family. This act of human bravery called Besa, if notice or found out by the Nazis had fatal consequences for the whole host family. This act illustrates how deep Besa is embedded in the Albanian culture and language even if it meant taking extreme risks.

Another noticeable characteristic of Albanian language and culture is that Albanians use the word "I" a lot more than "we" or "our". This is to pride ourselves rather than the group or a collective. Such an attitude shows that Albanian culture is more individualistic compare to many Western and Far Eastern cultures, such as Korean and Japanese cultures, which are very communal cultures and have very few individualistic words. Communal cultures of many Western countries and Far Eastern countries have contributed considerably to their countries' prosperity and development, and they have helped their countries to be more conservative and protective, too. In particular, Korean language never uses the pronouns "I" and "my" but instead it uses the pronouns "we" and "our". This characteristic, of priding themselves rather than the group or the collective, is also the result of an Albanian's way or 
attitude of thinking that an individual is more important than the group in which the individual is involved. Even in extreme cases when the individual gets it wrong and betrays the whole group for his/her own interests or benefits. Nevertheless, Albanian culture has a tendency to regard an individual's profit more than the group's profit but this selfish or individualistic attitude has inhibited the Albanian people and their country to grow and to prosper economically when compared to other nations with different language and culture backgrounds, and this, despite those nations or countries not being better positioned geographically or having more natural resources.

In addition, another noticeable characteristic of the Albanian language and its culture is that, Albania, or any areas inhabited by Albanians, has a bad economic efficiency reflecting the Albanian peoples' preferences to do things slowly or to procrastinate. Even for the smallest issues they tend to meet several times and discuss the same problem or issue over and over again. Most notably, when they agree on something, they tend to have a verbal agreement with nothing being written or recorded which has unprecedented consequences in the future. This selfish or intentional habit needs to change if Albania wishes to compete with countries with better economies or where the people have a tendency to do things more quickly and efficiently; countries such as: USA, Canada, Germany, Korea, Japan, Great Britan and many other western developed countries. This particular cultural attitude gives the impression that Albanian men (Albanian women tend to be hard working) form a lazy workforce that favors the Spanish lazy attitude for "Mańana" or having pleasure before work; a direct contrast to the German working attitude, "Erst mal arbeit und dann vergnügen", (first work, then pleasure).

Lastly, in contrast to the previous two characteristics, the Albanian language uses many expressions associated with the word "family". The family is very important to Albanian people. It is associated with unity, trust, value and it is considered the most stable institution that offers assurance and support. It offers unity to all the members of family and they are led by one person who, in most cases, is the oldest in the family but who has to be a good role model for the rest of the family members. It offers trust to all the members of the family, led by the most trustworthy member of the family, who is able to reduce conflicts and disagreements among family members. It offers great value that keeps all the family members together. Togetherness, however, offers assurance and support to the most vulnerable members of the family. Therefore, families members prefer to live together; husband, wife, children, father, mother, brothers and sisters and help each other in many ways. By being together and remaining together as a family, Albanian people regard collective unity in a family environment as a strong value and route to economic security and growth.

\subsection{Research Questions}

With an aim to examine how an Indo-European language like Albanian language and a unique individualistic culture like Albanian one has affected their people so profoundly in overall behavior and management of their well-being, this study will try and find answers to the following two questions:

- What is the effect of Albanian language and its traditional culture in overall behavior and management of the Albanian people and their well-being?

- What is the major cause of the Albanian efficiency in economy?

\section{Results and Discussion}

From the above noticeable characteristics of the Albanian language and culture, and other significant references results that language, apart from being a mirror that reflects a culture, behavior and management of the Albanian people in general, it also deals with the sounds, symbols and gestures that a nation, a tribe or a community uses as a means of communication. But if we go to a deeper level, language is also an expression of who we are as individuals, as communities or even as nations. Whereas, culture refers to dynamic social systems and shared patterns of behavior, beliefs, knowledge, attitudes and values and above all, provides the environment in which language develops, even as it influences how these issues are used and interpreted. For example, in many European cultures, including Albanian culture, a "good day" is a sunny day, while in many African cultures a "good day" is a rainy day. Different culturally shared values provide the context for interpreting the term for "good".

It is discussed and argued that the values and customs of our culture shape the way we think and behave to a certain extent and the way we do things inefficiently to a large extent. In addition, language not only provides us with the important tools we use to express our thoughts and ideas on daily basis communication, but it also expresses who we are as individuals, communities or even as whole nations.

\section{Conclusions}

Much has been said, written and researched over the years and centuries, with regard to different aspects of languages and cultures; the different effects that they have on one another, the different influence that they have on one another, the different exposure that they have on one another, and the different support and protection they offer to one another. This work has been carried out by many eminent language researchers, theorists, linguists, educational psychologist and an ocean of scholars in different parts of the world. The conclusion of this body of 
knowledge is that language is an integral part of culture, the usage of a given word is peculiar to a language and its relationship with culture and, importantly, through language we can express cultural beliefs and values.

\section{REFERENCES}

[1] Ayumi. Cultures hiding in languages. Retrieved on the $11^{\text {th }}$ of April, 2017 from, http://www.lexiophiles.com/english/c ultures-hiding-in-languages, 2009.

[2] M, Byran. Cultural studies in foreign language education. Multilingual Matters LTD, 1989.

[3] M, Byran\&V.E, Sarries. Investigating cultural studies in foreign language teaching. Multilingual Matters LTD, 1989.

[4] M, Clyne. Intercultural communication. Cambridge Unive rsity Press, 1994.

[5] H.D, Dodd. Intercultural communication. WM.C. Brown Publisher, 1997.

[6] Emma. The relationship between language and culture. Retrieved on the $12^{\text {th }}$ of April, 2017 from, http://www.lexi ophiles.com/uncategorized/the-relationship-between-langu age-and-culture, 2010

[7] F, Guessabi.Blurring the line between language and culture. Retrieved on the $10^{\text {th }}$ of April, 2017 from, http://language magazine.com/blurring-the-line-between-language-and-cul ture/, 2015.

[8] W, Jiang. The relationship between culture and language. ELT J 2000; 54 (4): 328-334. doi:10.1093/elt/54. 4.328, 2000.

[9] J.C, Kramsch. Language and culture. Oxford. Oxford University Press, 1998.

[10] A.L, Kroeber. American culture and the northwest coast. American Anthropologist, 25: 1-20.doi:10.1525/aa.1923.2 5.1.02a00020, 1923.

[11] D. Lingo. Albanian culture for kids-food, festivals, clothes, language, and so much more. Retrieved on the $13^{\text {th }}$ of April, 2017 from,http://dinolingo.com/blog/2012/11/14/albania-c ulture-food-festivals-clothes-and-so-much-more/\#.Vcu3M WOwWI4, 2012.

[12] Sujeong. An insight into Korean culture through Korean language. Retrieved on the $13^{\text {th }}$ of April, 2017 from, http://www.lexiophiles.com/english/an-insight-into-korean -culture-through-the-korean-language, 2009. 